\title{
Analysis of genotype $\times$ environment interaction in rain-fed durum wheat of Iran using GGE-biplot and non-parametric methods
}

\author{
Reza Mohammadi ${ }^{1}$ and Ahmed $\mathrm{Amri}^{2}$ \\ ${ }^{1}$ Dryland Agricultural Research Institute (DARI), P.O. Box 67145-1164, Kermanshah, Iran \\ (e-mail: rmohammadi95@yahoo.com); and ${ }^{2}$ International Center for Agricultural Research in the Dry Areas \\ (ICARDA), Aleppo, Syria. Received 10 July 2011, accepted 3 October 2011.
}

\begin{abstract}
Mohammadi, R. and Amri, A. 2012. Analysis of genotype $\times$ environment interaction in rain-fed durum wheat of Iran using GGE-biplot and non-parametric methods. Can. J. Plant Sci. 92: 757-770. Multi-environment trials (MET) are conducted annually throughout the world in order to use the information contained in MET data for genotype evaluation and mega-environment identification. In this study, grain yield data of 13 durum and one bread wheat genotypes grown in 16 diversified environments (differing in winter temperatures and water regimes) were used to analyze genotype by environment (GE) interactions in rain-fed durum MET data in Iran. The main objectives were (i) to investigate the possibility of dividing the test locations representative for rain-fed durum production in Iran into mega-environments using the genotype main effect plus GE interaction (GGE) biplot model and (ii) to compare the effectiveness of the GGEbiplot and several non-parametric stability measures (NPSM), which are not well-documented, for evaluating the stability performance of genotypes tested and the possibility of recommending the best genotype(s) for commercial release in the rain-fed areas of Iran. The results indicate that the grain yield of different genotypes was significantly influenced by environmental effect. The greater GE interaction relative to genotype effect suggested significant environmental groups with different top-yielding genotypes. Warm environments differed from cold environments in the ranking of genotypes, while moderate environments were highly divergent and correlated with both cold and warm environments. Cold and warm environments were better than moderate environments in both discriminating and representativeness, suggesting the efficiency and accuracy of genotype selection would be greatly enhanced in such environments. According to the NPSM, genotypes tend to be classified into groups related to the static and dynamic concepts of stability. Both the GGE-biplot and NPSM methods were found to be useful, and generally gave similar results in identifying high-yielding and stable genotypes. In contrast to NPSM, the GGE-biplot analysis would serve as a better platform to analyze MET data, because it always explicitly indicates the average yield and stability of the genotypes and the discriminating ability and representativeness of the test environments.
\end{abstract}

Key words: Multi-environment trials, GGE-biplot, non-parametric stability measures, genotype evaluation, test environment, grain yield, durum wheat

\begin{abstract}
Mohammadi, R. et Amri, A. 2012. Analyse des interactions génotype $\times$ environnement chez le blé dur cultivé sans irrigation en Iran au moyen de la méthode GGE à double projection et de méthodes non paramétriques. Can. J. Plant Sci. 92: 757-770. Chaque année, on procède à des essais multi-environnementaux (EME) partout dans le monde, puis les données recueillies dans le cadre de ces essais servent à évaluer les génotypes et à identifier les méga-environnements. Dans le cadre de la présente étude, on a utilisé les données sur le rendement grainier de 13 génotypes de blé dur et d'un génotype de blé panifiable cultivés dans 16 milieux différents (température hivernale et régime pluvial) pour voir si l'on pourrait analyser les interactions du génotype et de l'environnement (GE) à partir des données issues des EME sur le blé dur cultivé sans irrigation en Iran. Les principaux objectifs consistaient (i) à déterminer si l'on peut répartir les sites d'essais représentatifs de la culture non irriguée du blé dur en Iran en méga-environnements grâce au modèle GGE à double projection (effet principal venant du génotype plus interactions GE) et (ii) à comparer l'efficacité du modèle GGE à double projection à celle de diverses mesures non paramétriques de la stabilité (MNPS), une méthode mal documentée, pour évaluer la stabilité du rendement des génotypes testés et pour voir si l'on pourrait recommander de meilleurs génotypes en vue d'une homologation commerciale dans les régions non irriguées du pays. Les résultats indiquent que le rendement grainier des génotypes subit sensiblement l'influence de l'environnement. La principale interaction GE associée à un effet génotypique laisse croire qu'il existe d'importants groupes environnementaux, et que les génotypes au rendement le plus élevé diffèrent entre ces groupes. Ainsi, un climat chaud entraîne un classement de génotypes différent de celui obtenu avec un climat froid, alors qu'un environnement tempéré se caractérise par maintes divergences, que l'on peut corréler à la fois aux environnements chauds et aux environnements froids. D'autre part, les environnements chauds et froids assurent une discrimination et une représentativité supérieures à celles des environnements tempérés, ce qui donne à penser que la sélection des génotypes serait considérablement plus efficace et précise dans de telles conditions. Avec les MNPS, les
\end{abstract} interaction; Met, multi-environment trials; NPSM, non-parametric stability measures; RS, rank-sum 
génotypes ont tendance à se regrouper selon les concepts statiques et dynamiques de la stabilité. La méthode GGE à double projection et les MNPS ont leur utilité et donnent des résultats généralement semblables lorsqu'il s'agit d'identifier des génotypes stables à haut rendement. Contrairement aux MNPS, l'analyse GGE à double projection permet une meilleure analyse des données EME, car elle indique toujours explicitement le rendement moyen et la stabilité du génotype, ainsi que le pouvoir discriminatoire et la représentativité de l'environnement d'essai.

Mots clés: Essais multi-environnementaux, analyse GGE à double projection, mesures non paramétriques de la stabilité, évaluation du génotype, environnement d'essai, rendement grainier, blé dur

Durum wheat (Triticum turgidum L. var. durum Desf.) is grown on $10 \%$ of the world's wheat-growing area. It occupies about 11 million ha in the Mediterranean basin. Rainfall and temperatures in Mediterranean dryland areas show large and unpredictable fluctuations within and over several cropping seasons. In Iran, durum wheat is cultivated across diverse environments, ranging from warm lowlands to cold highlands (Mohammadi et al. 2011). Iran is prone to severe drought every 5-7 yr. Supplemental irrigation could help in preventing crop failure during droughts and improve yields in cropping seasons with average precipitation. The success of durum wheat in Iran, as a food security crop, is largely due to its good ability and capacity to yield well under drought prone, marginal and poor management conditions where other crops would fail (Mohammadi et al. 2011). The improved durum wheat genotypes are evaluated in multi-environment trials (MET) to test their performance across environments and to select the best genotypes in specific environments or stable performing genotypes across a range of environments. A genotype grown in different environments will frequently show significant fluctuation in yield performance. These changes are influenced by the different environmental conditions and are referred to as genotype-by-environment (GE) interaction (Allard and Bradshaw 1964). GE interaction continues to be a challenging issue among plant breeders, geneticists, and production agronomists who conduct crop performance trials across diverse environments. GE interaction can reduce progress from selection (Rao and Prabhakaran 2005). However, the GE interactions complicate the identification of superior genotypes, but their interpretation can be facilitated by the use of several statistical modeling methods. These models can be linear formulations, such as joint-regression (Yates and Cochran 1938; Eberhart and Russell 1966), multivariate clustering techniques (Lin and Butler 1990), multiplication approaches, such as additive mean effects and multiplicative interaction (Zobel et al. 1988; Gauch 1992), genotype plus GE (GGE) biplot analysis (Yan et al. 2000), and parametric and non-parametric stability methods (Huehn 1979). Modeling GE interaction in MET helps to determine phenotypic stability of genotypes, but this concept has been defined in different ways, and increasing numbers of stability parameters have been developed (Gauch and Zobel 1996).
Yan et al. (2000) developed a "GGE-biplot" methodology for graphical analysis of MET data. The GGEbiplot is constructed by plotting the first two principal components ( $\mathrm{PC1}$ and $\mathrm{PC} 2$ ) derived from singular value decomposition of the environment-centered data. Increasingly, plant breeders/agronomists have found GGE-biplots useful in mega-environment analysis (Yan et al. 2001; Yan and Rajcan 2002; Casanoves et al. 2005; Samonte et al. 2005; Yan and Tinker 2005; Dardanellia et al. 2006), genotype evaluation (Bhan et al. 2005; Malvar et al. 2005; Voltas et al. 2005; Kang et al. 2006; Fan et al. 2007), test-environment evaluation (Yan and Rajcan 2002; Blanche and Myers 2006; Thomason and Phillips 2006; Dimitrios et al. 2008), trait-association, and trait-profile analyses (Yan and Rajcan 2002; Morris et al. 2004; Ober et al. 2005). However, the GGE-biplot can visually address many questions relative to genotype and test environment evaluation. By applying the GGE-biplot, genotypes can be evaluated for their performance in individual environment and also across environments, mean performance and stability, and general or specific adaptations. Simultaneously, environments can be visually evaluated and grouped on the basis of their ability to discriminate among genotypes and their representativeness of other test environments. In addition, a GGE-biplot can reveal the "which-wonwhere" pattern of a MET data, which is important for mega-environment identification and for genotype recommendations specific to each mega-environment (Yan and Tinker 2005).

A number of parametric (univariate and multivariate) and non-parametric stability measures have been developed over the years to analyze GE interaction and especially yield stability over environments. Huehn (1996) indicated that there are two major approaches for studying GE interaction to determine the adaptation of genotypes. The first and most commonly used approach is parametric, which relies on distributional assumptions about genotypic, environmental, and GE interaction effects. The second is the non-parametric approach, which does not need any assumptions. Nonparametric stability procedures proposed by Huehn (1979), Nassar and Huehn (1987), Kang (1988) and Fox et al. (1990) are based on the ranks of genotypes in each environment, and the genotypes with similar ranking across environments are classified as stable. Non-parametric methods have some advantages over parametric stability methods. They reduce the bias 
caused by outliers and no assumptions are needed about the distribution of observed values. They are easy to use and interpret, and additions or deletions of one or a few genotypes have little effect on the results (Huehn 1990a). Furthermore, if the breeder is only interested in the existence of rank order differences over different environments, the non-parametric statistics for GE interactions based on ranks provide a useful alternative to parametric statistics approaches currently used, which are based on absolute data. In these cases, the relative characteristics and comparisons of the genotypes are more important than absolute characterization and comparisons.

Each of the two statistical approaches of GGEbiplot and non-parametric methods are well reviewed and documented in different crops, but little is known about comparing these two approaches for genotype evaluation in MET data. However, the main objectives of this study were (i) to investigate the possibility of dividing the rain-fed durum testing locations (differing in winter temperatures and water regimes) into megaenvironments using GGE-biplot method, and (ii) to compare the effectiveness of the GGE-biplot and nonparametric stability methods to identify high-yielding and stable genotypes.

\section{MATERIALS AND METHODS}

\section{Experimental Data}

The grain yields of 14 genotypes (13 durum and one bread wheat genotypes) grown in 16 diversified environments were subjected to analysis of the GE interaction in rain-fed durum MET data in Iran. The genotypes were evaluated in the three research sites (differing in winter temperature) representing major durum rain-fed growing areas during four cropping seasons (2006-2009) within the collaboration between Iran and ICARDA. These research sites can be regarded as moderate (Kermanshah location), warm (Ilam location) and cold (Shirvan location) locations (Mohammadi et al. 2010a, 2011). More details on test environments are presented in Table 1. The 14 genotypes consisted of 11 breeding lines selected from the final stage of the durum breeding program for rain-fed conditions of Iran, two durum (Zardak) and bread (Sardari) wheat landraces and one newly durum released variety (Saji). More details on tested genotypes are given in Table 2. The trials in all environments were conducted under rain-fed conditions and in some were also conducted under supplemental irrigation conditions (one or two irrigations with $25 \mathrm{~mm}$ at each irrigation applied either at flowering and/or at grain filling stages) (Table 1) to cope with terminal drought stress, which is a common feature in durum breeding in Iran. However, due to severe drought conditions in the 2007-2008 cropping season, no data were recorded at the warm and cold locations, but in the moderate location both rain-fed and irrigated trials received $30 \mathrm{~mm}$ of irrigation before the flowering stage in order to avoid crop failure (Table 1).

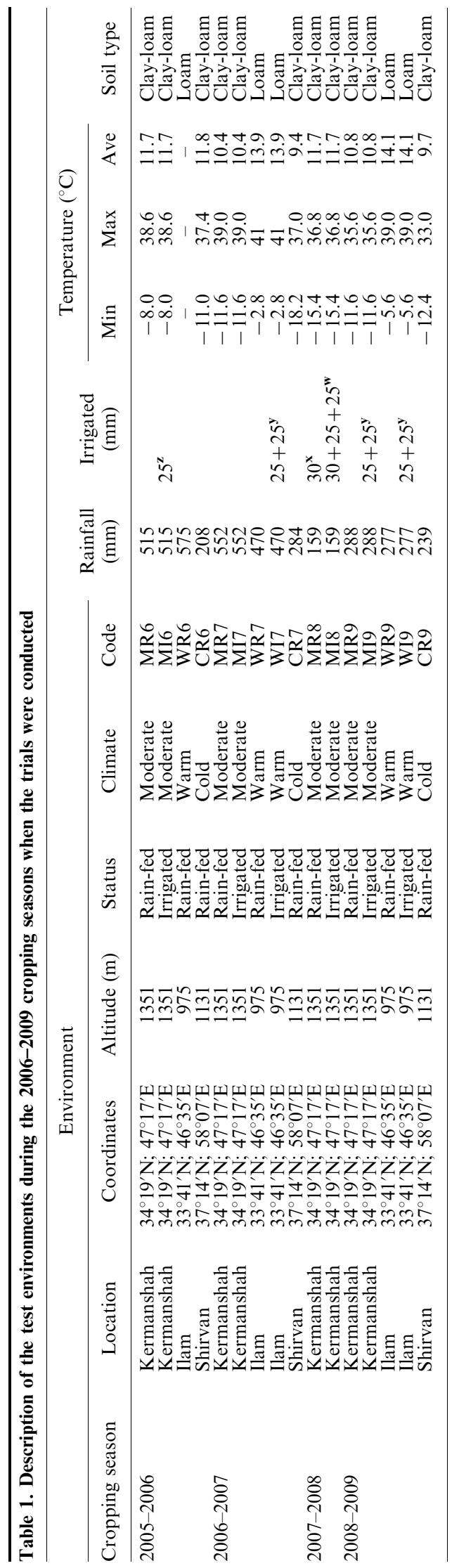

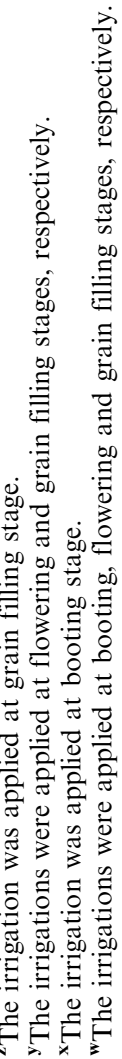




\begin{tabular}{lll}
\hline \multicolumn{2}{l}{ Table 2. Code and origin of the genotypes tested } \\
\hline Code & \multicolumn{1}{c}{ Genotype } & Origin \\
\hline G1 & Waha B53 & ICARDA \\
G2 & Arthur71/Bcr//Ch5 & ICARDA \\
G3 & Stj3/4/Stn//Hui/Somo/3/Yav/Fg//Roh & ICARDA \\
G4 & Gidara-2 & ICARDA \\
G5 & Lgt3/4/Bcr/3/Ch1//Gta/Stk & ICARDA \\
G6 & Aghrass-2 & ICARDA \\
G7 & Quadalete//Erp/Mal/3/Unk/4/Mrb3/Mna-1 & ICARDA \\
G8 & Stj3//Bcr/Lks4 & ICARDA \\
G9 & Bicrederaa-1 & ICARDA \\
G10 & Ossl-1/Stj-5 & ICARDA \\
G11 & Bcr//Memo/Goo/3/Stj7 & ICARDA \\
G12 & Saji & Iran \\
G13 & Zardak & Iran \\
G14 & Sardari & Iran
\end{tabular}

At each environment, experimental layout was a randomized complete block design with three replications. Plot size was $7.2 \mathrm{~m}^{2}$ (six rows, $6 \mathrm{~m}$ long and $20-\mathrm{cm}$ row spacing). Fertilizer rate was $50 \mathrm{~kg} \mathrm{~N} \mathrm{ha}^{-1}$ and $50 \mathrm{~kg} \mathrm{P}_{2} \mathrm{O}_{5}$ $\mathrm{ha}^{-1}$ applied at planting. The grain yield data were recorded for each genotype at each environment and were subjected to data analysis.

\section{Statistical Analysis}

\section{Combined ANOVA}

The yield data were subjected to combined analysis of variance to partition yield variation into environments, genotypes, and GE interaction effects. Combined analysis of variance was performed using MSTATC software (Michigan State University 1991).

\section{GGE-biplot Analysis}

The GGE-biplot method (Yan et al. 2000) was employed to analyze the genotype by environment interaction of yield. It is based on the formula:

$$
Y_{i j}-\bar{Y}_{. j}=\lambda_{1} \xi_{i 1} \eta_{j 1}+\lambda_{2} \xi_{i 2} \eta_{j 2}+\varepsilon_{i j}
$$

where $Y_{\mathrm{ij}_{1}}$ is the average yield of genotype $i$ in environment $j ; \bar{Y}_{. j}$ is the average yield over all genotypes in environment $j ; \lambda_{1} \xi_{i 1} \eta_{j 1}+\lambda_{2} \xi_{i 2} \eta_{j 2}$ are collectively called the first principal component (PC1) and the second principal component (PC2); $\lambda_{1}+\lambda_{2}$ are the singular values for the first and second principal components, PC1 and PC2, respectively; $\xi_{i 1}+\xi_{i 2}$ are the PC1 and PC2 scores, respectively, for genotype $i ; \eta_{j 1}+\eta_{j 2}$ are the PC1 and PC2 scores, respectively, for environment $j$; and $\varepsilon_{i j}$ is the residual of the model associated with the genotype $i$ in environment $j$. Thus a GGE-biplot is constructed by plotting the PC1 scores against the PC2 scores for each genotype and each environment. The GGE-biplot methodology, which is composed of two concepts, the biplot concept (Gabriel 1971) and the GGE concept (Yan et al. 2000), was used to visually analyze the rain-fed durum MET data. This methodology uses a biplot to show the effects of G and GE that are important in genotype evaluation and that are also the sources of variation in GE interaction analysis of MET data (Yan et al. 2000, 2001). Using GGEbiplot methods, genotypes can be evaluated for their performance, stability, and adaptation in individual environments and across environments. Simultaneously, environment relationships can be evaluated and megaenvironment can be set up by using the biplots (Yan and Kang 2003).

Accordingly, the grain yield data were subjected to analyze of GE interaction using the GGEbiplot software (Yan 2001) (i) to generate graphs showing "which-wonwhere" patterns for mega-environment analysis, (ii) to rank genotypes based on yield and stability (iii) to compare genotypes with an ideal genotype (iv) to evaluate test locations for discriminating ability and representativeness (v) to calculate yield phenotypic correlation among test locations (vi) to rank genotypes relative to environment with the highest yielding, and (vii) to rank test environments relative to genotype with the highest-yielding performance. Angles between environment vectors were used to judge correlations (similarities/dissimilarities) between pairs of environments (Yan and Kang 2003).

\section{Non-parametric Stability Measures}

Three rank stability measures from Huehn (1979) and Nassar and Huehn (1987) were expressed as $S_{i}^{(2)}$, $\mathrm{S}_{\mathrm{i}}^{(3)}$ and $\mathrm{S}_{\mathrm{i}}^{(6)}$ and considered to stability analysis. For a two-way data set with $l$ genotypes and $m$ environments, we denote $r_{i j}$ as the rank of genotype $i$ in the environment $j$, and $\bar{r}_{i}$ as the mean rank across all environments for genotype $i$. The genotype with the highest yield was given a rank of 1 and that with the lowest yield was assigned a rank of $l$ ( $l=$ number of genotypes). Huehn's (1979) and Nassar and Huehn's (1987) stability measures based on yield ranks of genotypes in each environment are expressed as follows:

$$
\begin{aligned}
S_{i}^{(2)} & =\sum_{j=1}^{m}\left(r_{i j}-\overline{r_{i .}}\right)^{2} /(m-1) \\
S_{i}^{(3)} & =\sum_{j=1}^{m}\left(r_{i j}-\overline{r_{i .}}\right)^{2} / \overline{r_{i .}} \\
S_{i}^{(6)} & =\sum_{j=1}^{m}\left|r_{i j}-\overline{r_{i .}}\right| / \overline{r_{i .}}
\end{aligned}
$$

The $S_{i}^{(2)}$ gives the variance among the ranks over environments. For variance of ranks $\left(\mathrm{S}_{\mathrm{i}}^{(2)}\right)$, smaller estimates indicate relative stability and zero variance are an indication of maximum stability (Huehn 1990a). The $\mathrm{S}_{\mathrm{i}}^{(3)}$ and $\mathrm{S}_{\mathrm{i}}^{(6)}$ are the sum of the absolute deviations and sum of squares of ranks for each genotype relative to the mean of ranks, respectively. The genotypes with low values of these parameters can be regarded as stable. 
Kang's (1988) rank-sum (RS) is another nonparametric stability measure, which uses both yield and Shukla's (1972) stability variance. This index assigns a weight of one to both yield and stability statistic to identify high-yielding and stable genotypes. The genotype with the highest yield is given a rank of 1 and a genotype with the lowest stability variance is assigned a rank of 1 . All genotypes were ranked in this manner, and the ranks by yield and by stability variance are added for each genotype. The genotype with the lowest RS is the most desirable one. The stratified ranking technique of Fox et al. (1990) consists of scoring the number of environments in which each genotype ranked in the top, middle and bottom thirds of trial entries. The proportion of environments in which the genotype occurred in the top, middle and bottom third of the ranks was computed to form the non-parametric measures TOP, MID and LOW, respectively. Ranks were assigned to genotypes for each stability parameter and Spearman's coefficient of rank correlation was then determined for each of the possible pair wise comparisons of the ranks of the different stability statistics.

\section{Correlation Analysis Between GGE-Biplot and Non-parametric Stability Measures}

To study correlation between GGE-biplot and nonparametric stability measures in genotype rankings, the Spearman's correlation coefficients were calculated between yield ranks, stability ranks and yield-stability ranks obtained from GGE-biplot (Alwala et al. 2010) with the ranks given to each of the non-parametric stability measures. To obtain GGE-biplot yield ranks, the best rank was given to the ideal genotype, which is on the far right hand side, and the last rank was given to the genotype on the far left hand side of the biplot. The GGE stability rankings were determined as visual ratings on the projections of genotypes on the average environment coordinate (AEC) ordinate: a smaller projection equated to a better stability ranking. The GGE yield-stability rankings were determined as the sum of GGE yield and stability rankings.

\section{RESULTS AND DISCUSSION}

\section{ANOVA}

The combined ANOVA for grain yield revealed that environment, genotype, and GE interaction effects accounted for $89.3,0.70,4.99 \%$ of the total sum of squares, respectively (Table 3 ). The environment (E) portion in MET has been known to be the largest among all sources of variation, but it is regarded as irrelevant for genotype evaluation (Yan and Kang 2003). This is the reason that $\mathrm{E}$ is removed from the observed phenotypic data, which helps concentrate on genotype (G) and GE, which are relevant for genotype evaluation (Yan and Kang 2003; Fan et al. 2007). The GE interaction effect was about seven times greater than the $G$ effect. The large GE interaction, relative to the $G$ effect in this
Table 3. Combined analysis of variance for 14 genotypes grown in $\mathbf{1 6}$ environments

\begin{tabular}{lccr}
\hline Source & df & MS & $\%$ SST \\
\hline Environment (E) & 15 & $67524038^{* *}$ & 89.34 \\
Rep/E & 32 & 235647 & 0.67 \\
Genotype (G) & 13 & $612411^{* *}$ & 0.70 \\
GE & 195 & $289896^{* *}$ & 4.99 \\
Error & 416 & 117358 & 4.31 \\
Total & 671 & & \\
\hline
\end{tabular}

** Significant at the $1 \%$ level of probability; \%SST, percentage relative to the sum of squares total.

study suggests the possible existence of different megaenvironments with different top-yielding genotypes (Yan and Kang 2003).

\section{"Which-won-where" Pattern of GE Interaction in MET Data}

The polygon view of a biplot provides the best way to visualize the interaction patterns between genotypes and environments and to effectively interpret a biplot. It is drawn by connecting the genotype markers positioned furthest from the biplot origin using straight lines to form a polygon (or convex hull) such that all other genotype markers are contained within the polygon. Figure 1 shows a polygon view of GE interaction data for 14 genotypes across 16 environments. Environments that fall in different sectors have different best genotypes. Genotypes located near the biplot origin are less responsive to the change of environments. The vertex genotypes in this investigation were G8, G14 (Sardari, a bread wheat landrace), G13 (Zardak, a durum wheat landrace), G4 and G11 (Fig. 1). These genotypes were the best or the poorest genotypes in some or all of the environments since they had the greatest distance from the origin of the biplot (Yan and Kang 2003). The environments fell into four sections and the genotypes into five sections. From Fig. 1, the G14 (a bread wheat landrace) was more adapted to the cold (CR7, CR6) and moderate cold (MR8, MR9 and MR6) environments. The G8 (a durum experimental line) performed well in warm (WR6, WR9, WI7), moderate (MI7, MR7, MI9) and cold (CR9) environments. G11 was adapted to warm (WR7) and moderate (MI9) environments, and G4 (a durum experimental line) performed well in moderate (MI6) environments. G13 (a durum wheat landrace) was not the best yielding genotype at any environment. G8 and G14, with the greatest distance from the origin of the biplot, had the highest contribution to GE interaction. These two genotypes were highly adapted to 13 out of 16 test environments. These two genotypes were diverse in their adaptations, because G14 is a bread wheat landrace, which is highly adapted to cold and moderate cold rain-fed areas of Iran and is not recommend to be grown in warm areas (Mohammadi et al. 2010a, b, 2011), while G8 shows 


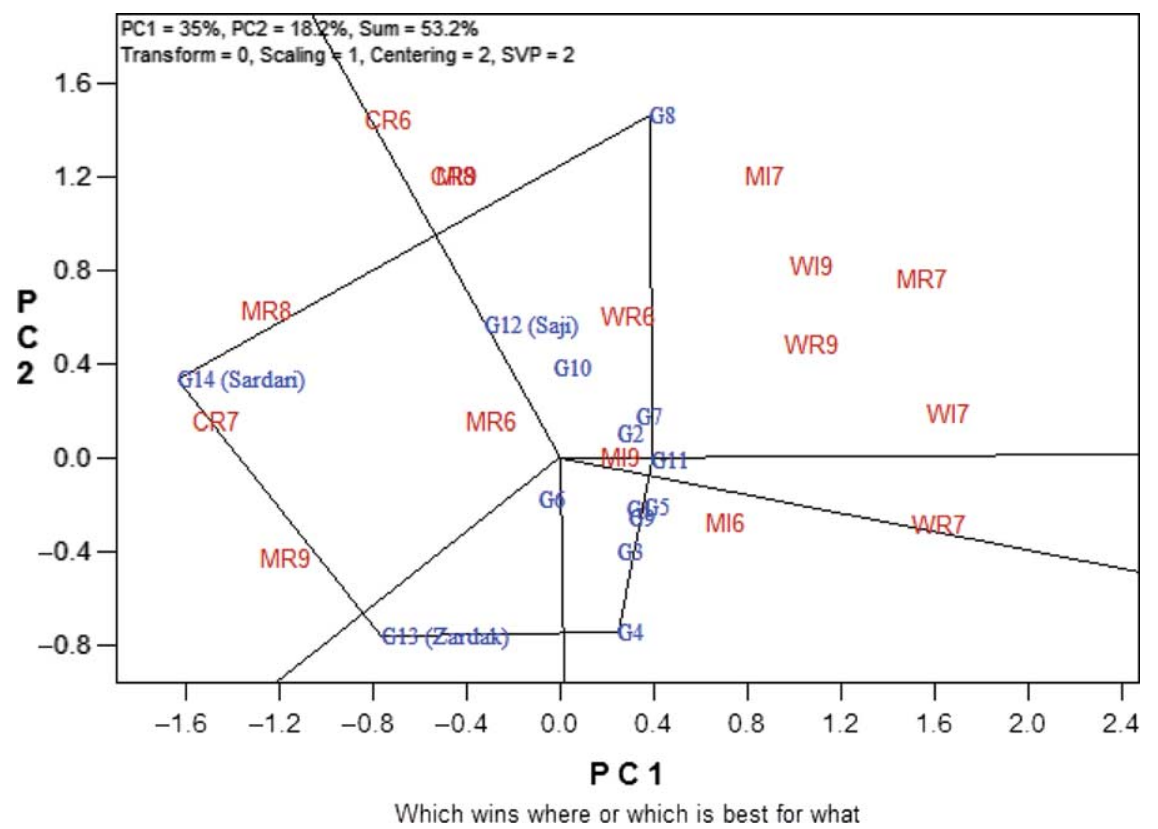

Fig. 1. Polygon view of GGE-biplot for 13 durum (G1-G13) and one bread wheat (G14) genotypes grown in 16 diversified environments. In the environment names, $\mathrm{M}, \mathrm{W}$ and $\mathrm{C}$ stand for moderate, warm and cold locations, respectively; R and I stand for rain-fed and irrigated conditions, respectively; and the numbers 6, 7, 8 and 9 stand for 2005-2006, 2006-2007, 2007-2008 and 2008-2009 cropping seasons, respectively. For details of environment and genotype codes see Tables 1 and 2, respectively.

high adaptation to environments representative of warm areas. In contrast, G6 with the shortest distance from the origin of the biplot gives the lowest contribution in the GE interaction, and can be considered a genotype with general adaptation. The environments corresponding to moderate locations tend to group with the environments corresponding to both cold and warm locations. It is well documented that in some years the moderate location ranks the genotypes as cold location and in some years as warm location (Mohammadi et al. 2010a, b, 2011).

\section{Ranking of Genotypes Based on Yield and Stability Performance}

A specific option in GGE-biplot analysis allows integrating yield with stability performance among a set of genotypes tested in MET data. Figure 2 shows the ranking of 14 genotypes based on their mean yield and stability performance across 16 diversified environments. The line passing through the biplot origin is called the average environment coordinate (AEC), which is defined by the average PC1 and PC2 scores of all environments (Yan and Kang 2003). The line which passes through the origin and is perpendicular to the AEC with double arrows represents the stability of genotypes. Either direction away from the biplot origin, on this axis, indicates greater GE interaction and reduced stability. From Fig. 2, genotype G8 followed by G12 (a new released durum variety) and G10 with the highest yield and stability performance can be considered as genotypes with high yield and stability performance. The other genotypes on the above side of the line with double arrows have yield performance greater than mean yield and those genotypes on the low side of this line had lesser yield than mean. The two durum (G13) and bread (G14) wheat landraces had low yield and stability. These results show that most of the breeding lines were more stable and were yielded more than the landraces. These results also confirm the superiority of G8 over cultivar Saji (G12; a newly released durum variety for moderate rain-fed regions of Iran) and it may be a good candidate for commercial release in rain-fed areas of Iran, where durum is grown.

\section{Evaluation of Genotypes Based on an Ideal Genotype}

An ideal genotype should have the highest mean performance and be stable. Although such an ideal genotype may not exist in reality, it can be used as a reference for genotype evaluation (Yan and Kang 2003). Thus, using the ideal genotype as the center, concentric circles were drawn to help visualize the distance between each genotype and the ideal genotype (Fig. 3). An ideal genotype, which is located at the center of the concentric circles in Fig. 3, is the one that has both high mean yield and high stability. Therefore, G8 can be regarded as an ideal genotype. Genotypes G12 and G10 were near to the ideal genotype. Ranking of other genotypes based on the ideal genotype was G7 $>\mathrm{G} 2>\mathrm{G} 11$. Genotypes G13, G4 and G3 were unfavorable because they were far away from the ideal genotype. 


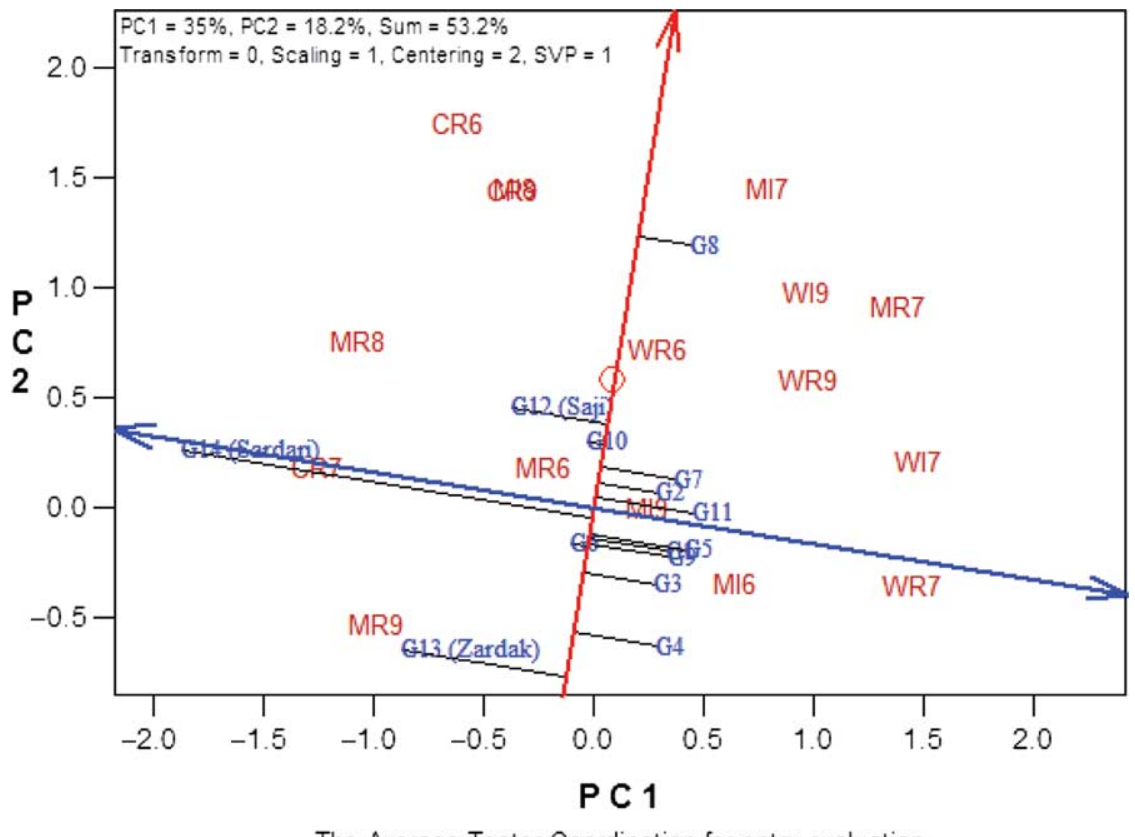

The Average Tester Coordination for entry evaluation

Fig. 2. GGE-biplot showing the ranks of genotypes based on both yield and stability performance. In the environment names M, W and $\mathrm{C}$ stand for moderate, warm and cold locations, respectively; $\mathrm{R}$ and I stand for rain-fed and irrigated conditions, respectively; and the number 6, 7, 8 and 9 stand for 2005-2006, 2006-2007, 2007-2008 and 2008-2009 cropping seasons, respectively. G1-G14 are the genotype codes. For details of environment and genotype codes see Tables 1 and 2, respectively.

\section{Evaluation of the Performance of Genotypes in a Specific Environment}

Figure 4 illustrates the graphic comparison of the relative performance of tested genotypes in environment MI7 (represents the moderate environment with supple- mental irrigation in 2006-2007), which produced the highest yield among the 16 environments. A line was drawn that passed through the biplot's origin and the MI7 marker to make a MI7-axis, and then an another line was drawn perpendicular from each genotype

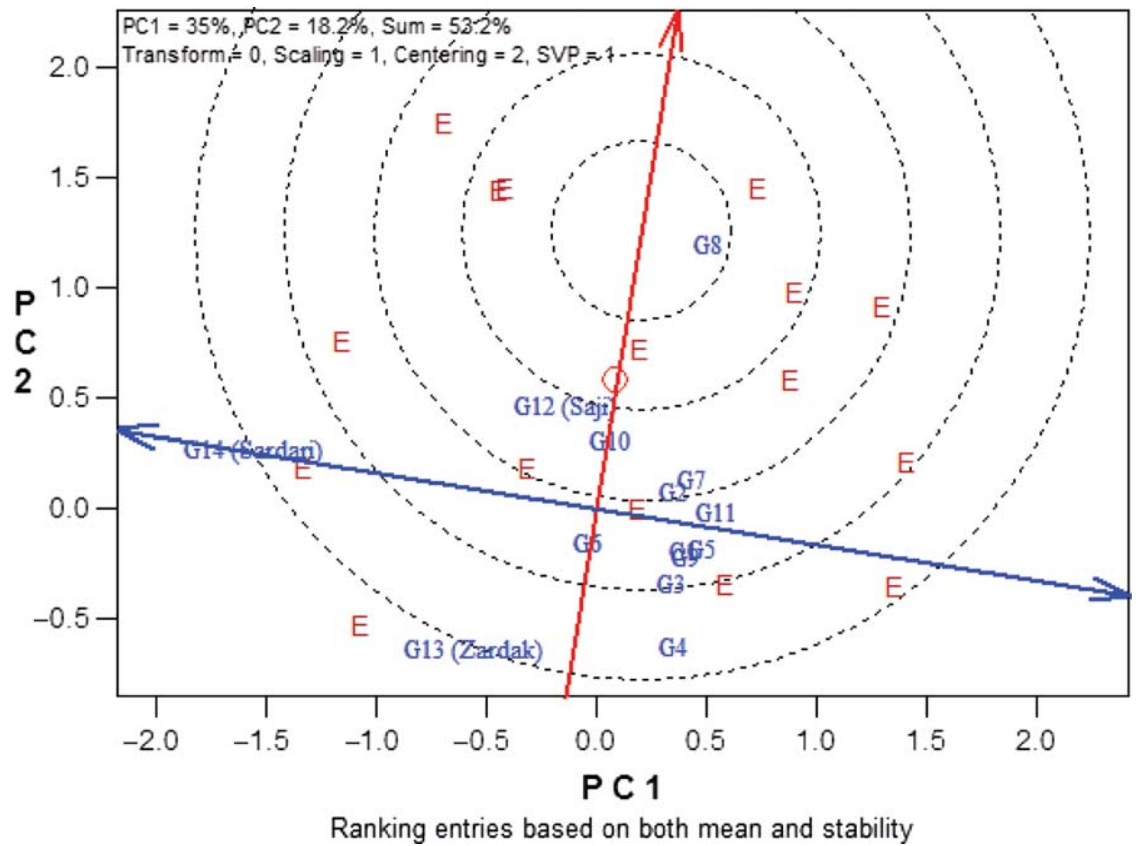

Fig. 3. GGE-biplot, which shows the evaluation of genotypes based on an ideal genotype. 


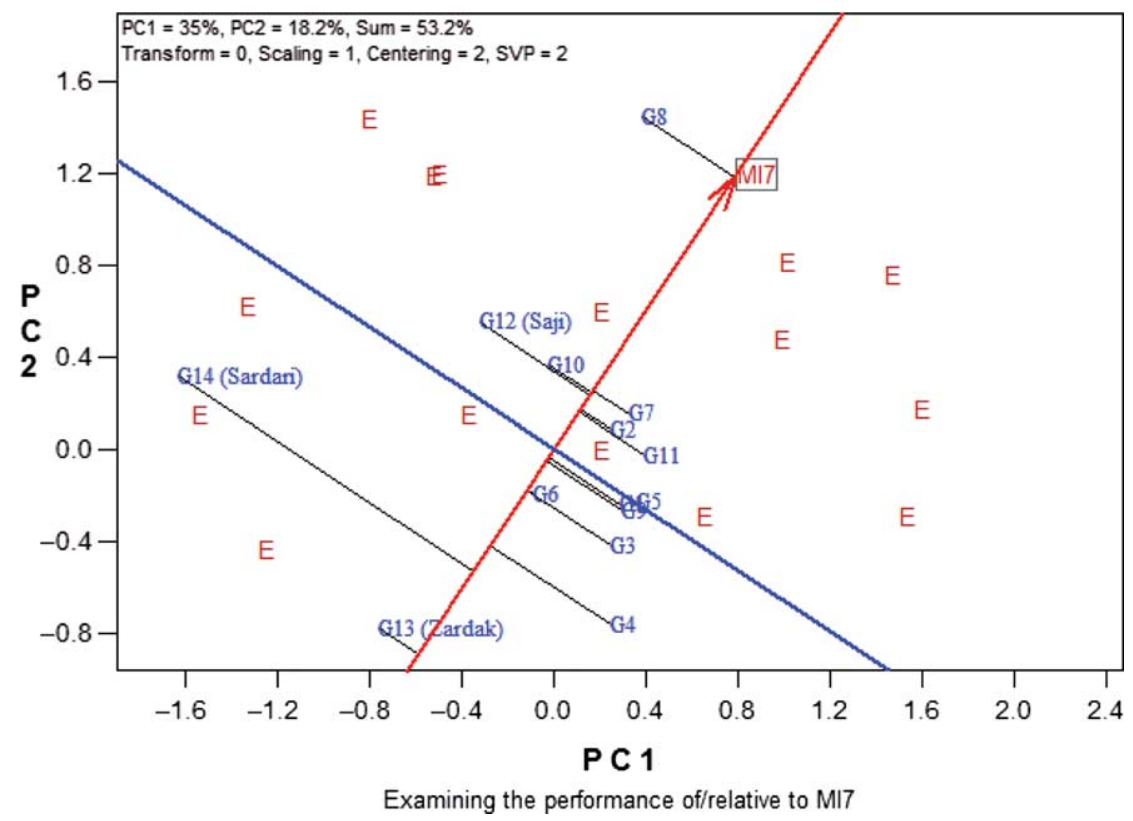

Fig. 4. Ranking of genotypes based on the highest yielding environment (MI7).

toward the MI7-axis. The genotypes were ranked on the basis of their projections onto the MI7-axis, with rank increasing in the direction toward the positive end (Yan et al. 2000). In environment MI7, genotype G8 had the highest yield followed by G7, G12 (cultivar Saji), G10, G2, G11, G5, G1, G9, G6, G3, G4, G14 (Sardari, a bread wheat landrace) and G13 (Zardak, a durum wheat landrace). The line that passed through the biplot's origin and was perpendicular to the MI7 environment vector separated the genotypes (G8, G7, G12, G10, G2, G11 and G5) that had higher yield than average yield from genotypes G1, G9, G6, G3, G4, G14 and G13, which had lower than average yield.

\section{Comparing the Relative Performance of a Specific Genotype Across Environments}

Figure 5 compares the relative performance of the highest yielding genotype (G8) at different environments. This is done by first drawing a straight line passing the biplot origin and the marker of genotype G8, then drawing a line perpendicular to this straight line from the environment. An environment's rank in producing G8 grain yield was based on its projection onto the G8 axis, with rank increasing in the direction toward the G8 marker (Yan et al. 2000). Hence, genotype G8 would yield highest at MI7 (moderate), CR6 (cold), MR7 (moderate), WI9 (warm), MI8 (moderate), CR9 (cold), WR9, WR6 and WI7 (warm), MR8 (moderate), WR7 (warm), MI9, MR6 and MI6 (moderate), CR7 (cold) and MR9 (moderate). The line that is perpendicular to the G8 vector and passing through the biplot's origin separates the environments at which G8 was above average from those (i.e., MI6, CR7 and MR6) at which G8 was below average.

\section{Evaluation of Test Environments}

Although MET data are used for genotype evaluation, they can also be used in environment evaluation. An ideal environment should be highly differentiating of the genotypes and at the same time representative of the target environment. Discriminating ability refers to a location's ability to maximize the variance among genotypes in a study (Blanche and Myers 2006). Representativeness suggests that a location is representative of the conditions of other locations included in the study. An ideal testing location combines both of these aspects for the development of generally adapted plant materials. In Fig. 6, the environments are ranked based on both discriminating ability and representativeness. In Fig. 6, the small circle is where an ideal environment should be; its projection on the AEC $\mathrm{x}$-axis was designed to be equal to the longest vector of all environments; therefore, it is the most discriminating; its projection on the AEC y-axis was obviously zero, meaning that it is absolutely representative of the average environment (Yan 2001). In Fig. 6 the ranking of environments in terms of being the most representative environment (based on the angle between the environment vector and AEC) were WR6 (rank of 1) followed by MI7 (2), MI8 (3), CR9 (4), CR6 (5), WI9 (6), MR7 (7), WR9 (8), WI7 (9), MI9 (10), MR8 (11), MR6 (12), WR7 (13), CR7 (14), MI6 (15), and MR9 (16) (Fig. 6). Warm location had an average rank of 7.4 [i.e., is calculated based on the ranks of five environments in warm location: $(1+6+8+9+13) / 5=7.4]$, while the cold and moderate locations had average ranks of 7.7 and 9.5, respectively. Accordingly, the warm location can be identified as more representative test site and consequently can be 


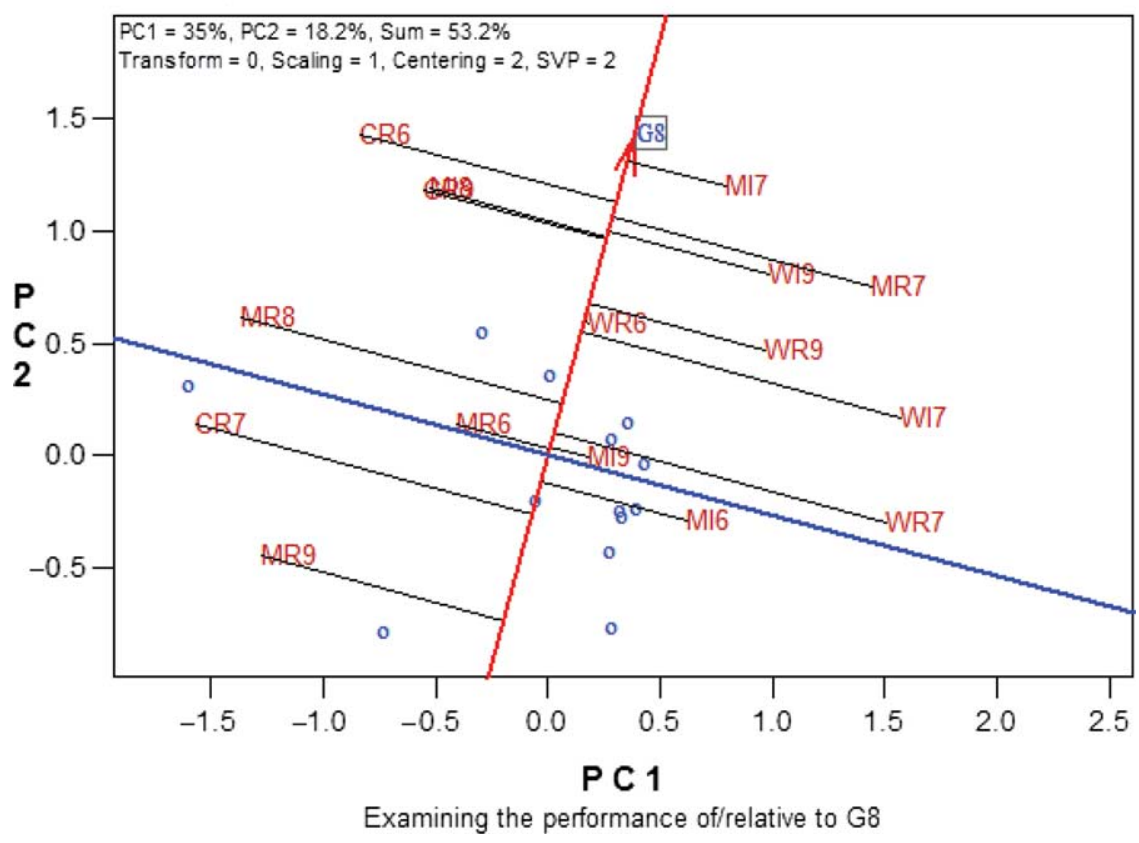

Fig. 5. Ranking of environments based on the highest yielding genotype (G8). In the environment names, M, W and C included stand for moderate, warm and cold locations, respectively; R and I stand for rain-fed and irrigated conditions, respectively; and the number 6, 7, 8 and 9 stand for 2005-2006, 2006-2007, 2007-2008 and 2008-2009 cropping seasons, respectively.

considered desirable for selecting durum genotypes adapted to the whole target region.

The ranking of environments in term of their ability to discriminate genotypes (based on length of their vectors) were MR7 (rank of 1) followed by CR6 (2), WI7 (3), WR7 (4), CR7 (5), MR8 (6), MI7 (7), MR9 (8), MI8 (9), CR9 (10), WI9 (11), WR9 (12), MI6 (13), WR6 (14), MR6 (15) and MI9 (16), respectively (Fig. 6). The cold location had an average rank of $5.7[(2+5+$ $10) / 3=5.7$, while warm and moderate locations had average ranks of 8.8 and 9.4, respectively. Thus, cold location can be identified as a location that had better overall genotype-discriminating ability than the other locations. Therefore, the cold location could serve as a trait-specific selection site either for selecting highyielding performance genotypes, or be used to develop genotypes adapted to specific cropping environments. In contrast to moderate location, the cold (most discriminating) and warm (most representatives) locations were better than in the both cases of discriminating and representativeness.

Figure 6 can also be used to indicate the testenvironments' representativeness of the mega-environment. Since the AEC abscissa is the "average-environment coordinate", test environments that have small angles with the AEC are more representative of the megaenvironment than those that have larger angles with the AEC (Yan et al. 2007). Based on Fig. 6, the test environments can be classified into three groups. Group I are those that have short vectors and provide little or no information about the genotypes and, therefore, should not be used as test environments. The test environments MI9, MR6, WR6 and MI6 can be identified based on this group. Group II environments have long vectors and small angles with the AEC abscissa and are ideal for selecting superior genotypes. The best environments based on this group were MI7, MR8, CR9, CR6, WI9 and MR7. If budgetary constraints allow only a few test environments, group II test environments are the first choice (Yan et al. 2007). Group III environments have long vectors and large angles with the AEC abscissa. The environments CR7, WR7, MR8 and WI7 can be characterized based on this group. These environments cannot be used in selecting superior genotypes, but are useful in culling unstable genotypes.

\section{Relationships Among Test Environments}

In GGE-biplot, the correlation coefficient between any two environments is approximated by the cosine of the angle between their vectors. Acute angles indicates a positive correlation, obtuse angles a negative correlation and right angles no correlation (Yan and Kang 2003). A short vector may indicate that the test environment is not related to other environments. According to Fig. 6, the maximum angle between the environments corresponding to cold location was well below 90 degrees, showing the environments (CR7, CR6 and CR9) represent for cold location are correlated in ranking of the tested genotypes. Similarly, the maximum angle between the environments (WR7, WI7, WR9, WI9 and WR6) corresponding to warm location was well below 90 degrees, indicating they tend to ranking of genotypes 


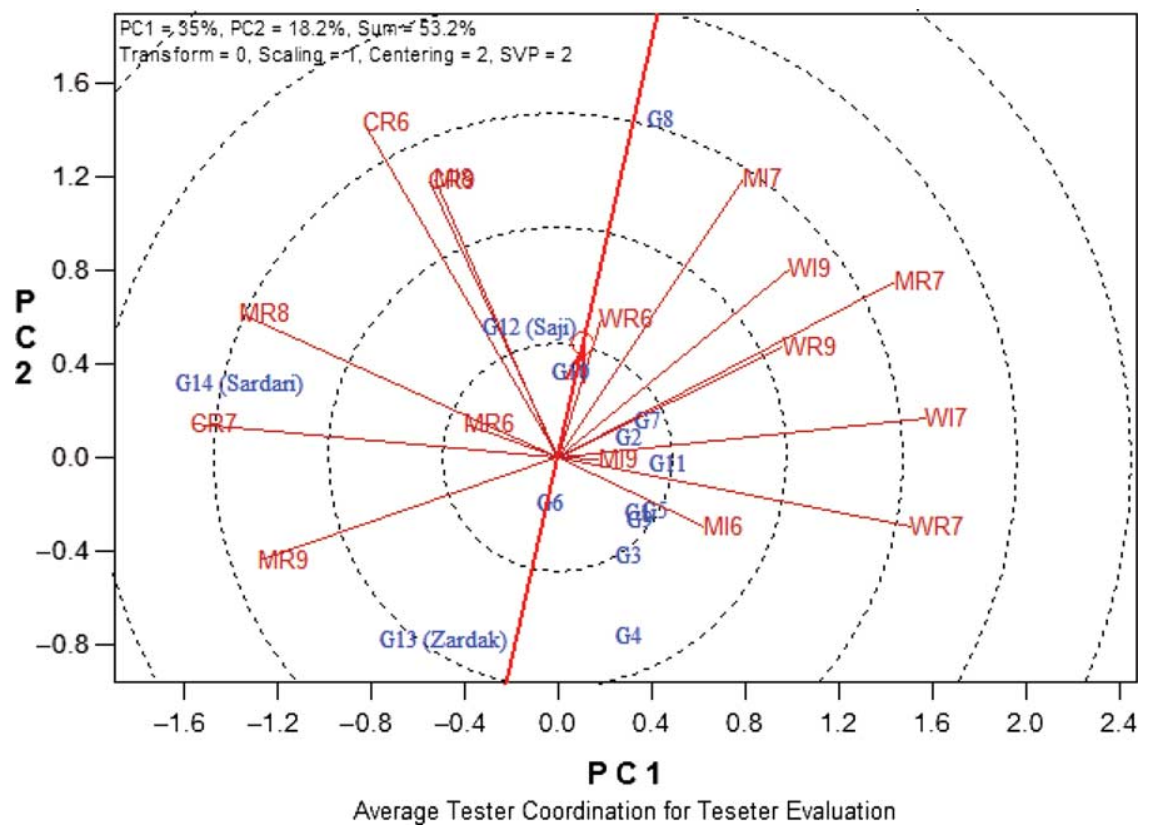

Fig. 6. GGE-biplot, which shows the discriminative vs. representativeness ability of environments.

In the environment names, $\mathrm{M}, \mathrm{W}$ and $\mathrm{C}$ stand for moderate, warm and cold locations, respectively; R and I stand for rain-fed and irrigated conditions, respectively; and the number 6, 7, 8 and 9 stand for 2005-2006, 2006-2007, 20072008 and 2008-2009 cropping seasons, respectively. G1-G14 are the genotype codes. For details of environment and genotype codes see Tables 1 and 2, respectively.

in similar fashion (Fig. 6). The environments corresponding to cold location were not correlated with those corresponding to warm location, showing these two locations are not associated in ranking of genotypes. In contrast, the environments corresponding to moderate location were not associated in ranking of genotypes, but they were correlated with the both cold and warm environments (Fig. 6).

\section{Genotype Evaluation Based on Non-Parametric Stability Measures}

The estimates of non-parametric stability measures for the tested genotypes and the ranks of genotypes based on these measures are given in Table 4. Taking the mean yield as the first priority for evaluating the genotypes, G8 followed by G12, G11 and G4 gave the best mean yield, while G13 (durum landrace) followed by G14 (bread wheat landrace), G3 and G1 had the lowest mean yield across environments. The $\mathrm{S}_{\mathrm{i}}^{(2)}$ statistic is based on ranks of genotypes across environments (Nassar and Huehn 1987) and accordingly, the genotypes with fewer changes in rank are considered to be more stable (Becker and Leon 1988). According to this statistic, G12 (cultivar Saji), G10, G9 and G3 had the smallest changes in ranks and is thus, regarded as the most stable genotypes, unlike the two landraces (G14 and G13), G5 and G4.

Two other non-parametric statistics of Huehn (1979), $\mathrm{S}_{\mathrm{i}}^{(3)}$ and $\mathrm{S}_{\mathrm{i}}^{(6)}$, combine yield and stability based on yield ranks of genotypes in each environment. These parameters measure stability in units of the mean rank of each genotype (Huehn 1979). The lowest value for each of these statistics indicates maximum stability for a specific genotype. Based on the statistic $S_{i}^{(3)}$, G10, G3, G2 and G9 can be considered as high stable genotypes, while G14, G8, G5 and G4 can be regarded as unstable genotypes. As for $\mathrm{S}_{\mathrm{i}}^{(3)}$, the $\mathrm{G} 3, \mathrm{G} 2, \mathrm{G} 9$ and $\mathrm{G} 6$ were found to be stable genotypes based on the $S_{i}^{(6)}$ and the G8, G14, G5 and G11 as unstable genotypes. G8, with the highest mean yield among the genotypes tested, was an unstable genotype, while G12, second in mean yield, was found to be a stable genotype (Table 4).

According to the TOP parameter of Fox et al. (1990), G12 was an adapted genotype because it ranked in the top third of genotypes in a high percentage of environments (high top value, 69\%), followed by G8 (56\%) and G11 (50\%) (Table 4). The undesirable genotypes identified by this method (TOP) were G3, G9 and G2; and the MID values for these genotypes were 44, 44 and $38 \%$, respectively. The genotypes with the highest values of TOP had the lowest LOW values (Table 4). Therefore, breeders can recommend the best adapted genotypes using the method of TOP (Fox et al. 1990; Flores et al. 1998; Mohammadi and Amri 2008; Mohammadi et al. 2007, 2008). The RS (Kang 1988) is a non-parametric stability measure, which uses both yield and Shukla's stability variance (Shukla 1972). The genotypes with the lowest RS are the most favorable genotypes (Kang 1988). 


\begin{tabular}{|c|c|c|c|c|c|c|c|c|}
\hline Code & Yield & $\mathrm{S}_{\mathrm{i}}^{(2)}$ & $\mathrm{S}_{\mathrm{i}}^{(3)}$ & $\mathrm{S}_{\mathrm{i}}^{(6)}$ & TOP & MID & LOW & RS \\
\hline G1 & 2161 & 3.77 & 25.5 & 5.97 & 31 & 25 & 44 & 19 \\
\hline G2 & 2212 & 3.50 & 20.7 & 4.99 & 19 & 38 & 44 & 17 \\
\hline G3 & 2155 & 3.45 & 20.2 & 4.92 & 13 & 44 & 44 & 16 \\
\hline G4 & 2292 & 4.45 & 36.7 & 7.45 & 31 & 25 & 44 & 15 \\
\hline G5 & 2271 & 4.18 & 38.5 & 8.02 & 44 & 25 & 31 & 14.5 \\
\hline G6 & 2230 & 3.47 & 22.8 & 5.69 & 31 & 31 & 38 & 12 \\
\hline G7 & 2237 & 3.91 & 29.5 & 6.97 & 38 & 25 & 38 & 18 \\
\hline G8 & 2418 & 4.09 & 49.6 & 10.89 & 56 & 25 & 19 & 13 \\
\hline G9 & 2258 & 3.4 & 21.8 & 5.67 & 19 & 44 & 38 & 9 \\
\hline G10 & 2271 & 2.96 & 19.9 & 6.04 & 38 & 44 & 19 & 6.5 \\
\hline G11 & 2343 & 3.77 & 34.1 & 8.00 & 50 & 38 & 13 & 8 \\
\hline G12 & 2397 & 2.83 & 24.7 & 7.47 & 69 & 19 & 13 & 8 \\
\hline G13 & 2018 & 4.65 & 32.0 & 6.25 & 25 & 6 & 69 & 27 \\
\hline G14 & 2065 & 5.39 & 58.1 & 10.4 & 38 & 13 & 50 & 27 \\
\hline \multicolumn{9}{|l|}{ Ranks } \\
\hline G1 & 11 & 7.5 & 7 & 5 & 9 & 9 & 4.5 & 12 \\
\hline G2 & 10 & 6 & 3 & 2 & 12.5 & 4.5 & 4.5 & 10 \\
\hline G3 & 12 & 4 & 2 & 1 & 14 & 2 & 4.5 & 9 \\
\hline G4 & 4 & 12 & 11 & 9 & 9 & 9 & 4.5 & 8 \\
\hline G5 & 5.5 & 11 & 12 & 12 & 4 & 9 & 10 & 7 \\
\hline G6 & 9 & 5 & 5 & 4 & 9 & 6 & 7 & 5 \\
\hline G7 & 8 & 9 & 8 & 8 & 6 & 9 & 8 & 11 \\
\hline G8 & 1 & 10 & 13 & 14 & 2 & 9 & 11 & 6 \\
\hline G9 & 7 & 3 & 4 & 3 & 12.5 & 2 & 9 & 4 \\
\hline G10 & 5.5 & 2 & 1 & 6 & 6 & 2 & 12 & 1 \\
\hline G11 & 3 & 7.5 & 10 & 11 & 3 & 4.5 & 13 & 2.5 \\
\hline G12 & 2 & 1 & 6 & 10 & 1 & 12 & 14 & 2.5 \\
\hline G13 & 14 & 13 & 9 & 7 & 11 & 14 & 1 & 13.5 \\
\hline G14 & 13 & 14 & 14 & 13 & 6 & 13 & 2 & 13.5 \\
\hline
\end{tabular}

According to the RS statistic, G10, G11, G12, G9 and G6 had the lowest values and therefore were stable genotypes with high yield (Table 4). According to the RS statistic, the undesirable genotypes were G14, G13, G1, G7 and G2. However, the tested genotypes can be characterized based on their concept of stability. Genotype G12 can be identified as a genotype with dynamic stability because it was superior based on TOP and RS and it can also be considered as genotype with static stability because it was superior based on the $S_{i}^{(2)}$ statistic (Table 4). The G8 can be identified as a genotype with a dynamic concept of stability. In contrast, the two landraces (G13 and G14) were not characterized based on each of the dynamic and static concepts of stability, since they had the highest values of the $S_{i}^{(2)}$ statistic and were also characterized as inferior genotypes based on TOP and RS parameters. Genotypes G10, G9 and G3 with high MID values had low changes in ranks across environments, and can be regarded as stable genotypes, while the two landraces (G13 and G14) with the lowest MID values had the highest changes in ranks across environments (Table 4).

\section{Relationship among Non-parametric Stability Measures}

The Spearman's rank correlation coefficients between yield with each of the non-parametric stability measures and between each pair of non-parametric stability measures are given in Table 5. The TOP parameter as a concept of dynamic stability (Flores et al. 1998; Sabaghnia et al. 2006; Mohammadi and Amri 2008; Mohammadi et al. 2010c) was positively correlated $(P<$ 0.01 ) with mean yield. The RS was also significantly correlated with mean yield and can be considered as a parameter with dynamic concept of stability (Flores et al. 1998; Sabaghnia et al. 2006; Mohammadi and Amri 2008; Mohammadi et al. 2009) to select the highyielding stable genotypes. The Huhen's (1979) parameters were correlated with each other, while they were not associated with mean yield, showing they can be regarded as static (biological) parameters for selecting the stable genotypes. The MID was not correlated with mean yield, TOP and RS parameters, but it was significantly correlated with the parameters with biological concept of stability $\left(\mathrm{S}_{\mathrm{i}}^{(2)}, \mathrm{S}_{\mathrm{i}}^{(3)}\right.$ and $\mathrm{S}_{\mathrm{i}}^{(6)}$ ) (Table 5), showing this parameter can be regarded as a static (biological) parameter. Thus the genotypes with high MID values can be considered as general stable.

\section{Similarities/Dissimilarities between GGE-Biplot and Non-parametric Methods in the Evaluation of Genotypes}

The which-won-where pattern of GGE-biplot (Fig. 1) identified the G8 followed by G14 as the widely adapted genotypes to most of environment (13 out of 16 environments), while the TOP parameter identified the G12 followed by G8 as highly adapted genotypes. Based on the RS, which ranks the genotypes based on both 


\begin{tabular}{|c|c|c|c|c|c|c|c|}
\hline Methods & Yield & $\mathrm{S}_{\mathrm{i}}^{(2)}$ & $\mathrm{S}_{\mathrm{i}}^{(3)}$ & $\mathrm{S}_{\mathrm{i}}^{(6)}$ & TOP & MID & LOW \\
\hline$S_{i}^{(2)}$ & 0.26 & & & & & & \\
\hline$S_{i}^{(3)}$ & -0.18 & $0.84 * *$ & & & & & \\
\hline$S_{i}^{(6)}$ & -0.49 & $0.55^{*}$ & $0.87 * *$ & & & & \\
\hline TOP & $0.70^{* *}$ & -0.08 & -0.52 & $-0.85^{* *}$ & & & \\
\hline MID & 0.13 & $0.65^{*}$ & $0.70^{* *}$ & $0.61 *$ & -0.39 & & \\
\hline LOW & $-0.85^{* *}$ & $-0.55^{*}$ & -0.10 & 0.31 & $-0.69^{*}$ & -0.30 & \\
\hline RS & $0.76^{* *}$ & $0.68 * *$ & 0.33 & -0.04 & 0.40 & 0.53 & $-0.88 * *$ \\
\hline
\end{tabular}

*, ** Significant at the $5 \%$ and $1 \%$ level of probability, respectively.

yield and stability performance, G10, G11 and G12 were identified as high-yielding stable genotypes. These results, in general, can be confirmed by the GGE-biplot method (Fig. 2) where genotypes G8, G12, G10 were identified as high-yielding and stable genotypes. The both GGE-biplot and non-parametric methods gave similar results in identifying both landraces (G13 and G14) as low yielding and unstable genotypes (Table 4 and Fig. 2).

Spearmen's rank correlation coefficients between GGE-biplot and NPSM are given in Table 6. The GGE yield ranks were significantly associated with mean yield $(P<0.05)$ and TOP $(P<0.01)$, suggesting the TOP parameter and the option of GGE-biplot, which ranks genotypes relative to an ideal genotype, give similar results in genotype ranking. The LOW parameter was negatively associated with GGE yield ranks, indicating that the genotypes with low adaptation to environments (genotypes with high values of LOW parameter) are far from the ideal genotype in GGEbiplot.

Significantly positive correlations were found between GGE stability ranks with the $\mathrm{S}_{\mathrm{i}}^{(3)}, \mathrm{S}_{\mathrm{i}}^{(2)}$ and MID, showing these parameters are similar to GGE-biplot in ranking of stable genotypes. GGE yield-stability ranks were positively correlated with $\mathrm{S}_{\mathrm{i}}^{(2)}, \mathrm{S}_{\mathrm{i}}^{(3)}$, MID and RS. In conclusion, the results of correlation analysis between the NPSM and GGE-biplot methods show that the GGE yield rankings seem to be near reflections of TOP and mean yield compared with other NPSM, while GGE stability rankings are better reflected in $\mathrm{S}_{\mathrm{i}}^{(3)}, \mathrm{S}_{\mathrm{i}}^{(2)}$ and MID results than those from other NPSM, and, similarly, the GGE yield-stability rankings seem to be near reflections of $\mathrm{S}_{\mathrm{i}}^{(2)}$. In general the GGE-biplot and non-parametric applied methods were in agreement in ranking of genotypes based on their yield and stability performance. However, an exact match is not to be expected, because the biplot captured $53.2 \%$ of $(\mathrm{G}+$ $\mathrm{GE})$ variation. The relatively low goodness of fit reflects the complexity of the relationships among the durum test locations, which differ in climate and water regime conditions. However, comparison of these two methods is not already well documented. Thus, additional work on other crops would add clarification to these results. However, there is general agreement among researchers about the superiority of parametric methods over nonparametric methods in terms of power; but if one or more of the underlying parametric assumptions are severely violated, the power advantage may not be there. Thus, recommendations based on the non-parametric methods combined with multivariate methods can be used to formulate more plausible recommendations, which are based on the evidence from the data and less relying on the assumptions.

\section{CONCLUSION}

The greater GE interaction relative to genotype effect suggested significant environmental groups with different top-yielding genotypes. Both the cold and warm environments were better than in both cases of discriminating and representativeness, suggesting the efficiency and accuracy of genotype selection would be greatly enhanced in such environments. This paper demonstrates the usefulness of the both GGE-biplot and non-parametric methods in characterizing genotypes based on stability and integrating yield with

Table 6. Spearman's rank correlations between yield ranks, stability ranks and yield-stability ranks obtained from GGE-biplot with the mean yield and non-parametric stability measures

\begin{tabular}{|c|c|c|c|c|c|c|c|c|}
\hline \multirow[b]{2}{*}{ GGE } & \multirow[b]{2}{*}{ Mean yield } & \multicolumn{7}{|c|}{ Non-parametric statistics } \\
\hline & & $\mathrm{S}_{\mathrm{i}}^{(2)}$ & $\mathrm{S}_{\mathrm{i}}^{(3)}$ & $\mathrm{S}_{\mathrm{i}}^{(6)}$ & TOP & MID & LOW & RS \\
\hline Yield ranks & $0.55^{*}$ & 0.32 & 0.00 & -0.38 & $0.69^{* *}$ & 0.03 & $-0.66^{* *}$ & 0.43 \\
\hline Stability ranks & 0.17 & $0.59^{*}$ & $0.63^{*}$ & 0.46 & -0.14 & $0.59^{*}$ & -0.26 & 0.36 \\
\hline Yield-stability ranks & 0.33 & $0.57^{*}$ & 0.46 & 0.17 & 0.21 & 0.42 & -0.48 & 0.41 \\
\hline
\end{tabular}

$*, * *$ Significant at the $5 \%$ and $1 \%$ level of probability, respectively. 
stability performance. These two methods, in general, were similar in ranking of genotypes on the bases of stability and integrating yield with stability performance. The GGE-biplot method was a more efficient tool to analyze GE interaction, because it can provide the biplots and information on genotype, environment and their interaction, while the non-parametric methods give information only on genotype evaluation. The nonparametric methods, due to their relations with mean yield, provided useful information on the concept of dynamic and static stability of genotypes. However, if breeders would like to evaluate the genotypes across diverse environments, the non-parametric methods can be a good alternative for some options of GGE-biplot related to genotype evaluation.

\section{ACKNOWLEDGMENTS}

This work was part of a regional durum research project of the Dryland Agricultural Research Institute (DARI), Iran and sponsored by the Agricultural Research and Education Organization (AREO). We thank all members of durum project for contributions they have made. The authors thank three anonymous reviewers for their comments, discussions, and corrections on the manuscript.

Allard, R. W. and Bradshaw, A. D. 1964. Implication of genotype-environmental interaction in applied plant breeding. Crop Sci. 5: 503-506.

Alwala, S., Kwolek, T., McPherson, M., Pellow, J. and Meyer, D. 2010. A comprehensive comparison between Eberhart and Russell joint regression and GGE biplot analyses to identify stable and high yielding maize hybrids. Field Crops Res. 119: 225-230.

Bhan, M. K., Pal, S., Rao, B. L., Dhar, A. K. and Kang, M. S. 2005. GGE biplot analysis of oil yield in lemongrass. J. New Seeds 7: 127-139.

Becker, H. C. and Leon, J. 1988. Stability analysis in plant breeding. Plant Breed. 101: 1-23.

Blanche, S. B. and Myers, G. O. 2006. Identifying discriminating locations for cultivar selection in Louisiana. Crop Sci. 46: 946-949.

Casanoves, F., Baldessari, J. and Balzarini, M. 2005. Evaluation of multienvironment trials of peanut cultivars. Crop Sci. 45: $18-26$.

Dardanellia, J. L., Balzarinic, M., Martíneza, M. J., Cunibertib, M., Resnikd, S., Ramundaa, S. F., Herrerob, R. and Baigorrib, H. 2006. Soybean maturity groups, environments, and their interaction define mega-environments for seed composition in Argentina. Crop Sci. 46: 1939-1947.

Dimitrios, B., Christos, G., Jesus, R. and Eva, B. 2008. Separation of cotton cultivar testing sites based on representativeness and discriminating ability using GGE Biplots. Agron. J. 100: 1230-1236.

Eberhart, S. A. and Russell, W. A. 1966. Stability parameters for comparing varieties. Crop Sci. 6: 36-40.

Fan, X. M., Kang, M. S., Chen, H., Zhang, Y., Tan, J. and Xu, C. 2007. Yield stability of maize hybrids evaluated in multienvironment trials in Yunnan, China. Agron. J. 99: 220-228.
Flores, F., Moreno, M. T. and Cubero, J. I. 1998. A comparison of univariate and multivariate methods to analyze environments. Field Crops Res. 56: 271-286.

Fox, P. N., Skovmand, B., Thompson, B. K., Braun, H. J. and Cormier, R. 1990. Yield and adaptation of hexaploid spring triticale. Euphytica 47: 57-64.

Gabriel, K. R. 1971. The biplot graphic display of matrices with application to principal component analysis. Biometrika 58: 453-467.

Gauch, H. G. 1992. Statistical analysis of regional yield trials: AMMI analysis of factorial designs. Elsevier, London, UK.

Gauch, H. G. and Zobel, R. W. 1996. AMMI analysis of yield trials. In M. S. Kang and H. G. Gauch, eds. Genotype by environment ineraction. CRC Press, Boca Raton, FL.

Huehn, V. M. 1979. Beitrage zur erfassung der phanotypischen stabilitat. EDV Med iol 10: 112-117.

Huehn, M. 1990a. Non-parametric measures of phenotypic stability: part 1. Theory. Euphytica 47: 189-194.

Huehn, M. 1996. Non-parametric analysis of genotype $\times$ environment interactions by ranks. Pages 213-228 in M. S. Kang and H. G. Gauch, eds. Genotype by environment interaction. CRC Press, Boca Raton, FL.

Kang, M. S. 1988. A rank-sum method for selecting highyielding, stable corn genotypes. Cereal Res. Commun. 16: 113-115.

Kang, M. S., Aggarwal, V. D. and Chirwa, R. M. 2006. Adaptability and stability of bean cultivars as determined via yield-stability statistic and GGE biplot analysis. J. Crop Improv. 15: 97-120.

Lin, C. S. and Butler, G. 1990. Cluster analyses for analyzing twoway classification data. Agron. J. 82: 344-348.

Malvar, R. A., Revillaa, P., Butróna, A., Gouesnardc, B., Boyatc, A., Soengasa, P., Álvarezb, A. and Ordás, A. 2005. Performance of crosses among French and Spanish maize populations across environments. Crop Sci. 45: 1052-1057.

Mohammadi, R. and Amri, A. 2008. Comparison of parametric and non-parametric methods for selecting stable and adapted durum wheat genotypes in variable environments. Euphytica 159: 419-432.

Mohammadi, R., Abdulahi, A., Haghparast, R. and Armion, M. 2007. Interpreting genotype $\times$ environment interactions for durum wheat grain yields using non-parametric methods. Euphytica 157: 239-251.

Mohammadi, R., Aghaee, M., Haghparast, R., Pourdad, S. S., Rostaii, M., Ansari, M., Abdolahi, A. and Amri, A. 2009. Association among non-parametric measures of phenotypic stability in four annual crops. In $\mathrm{R}$. Mohammadi and $\mathrm{R}$. Haghparast, eds. Plant science in Iran. Middle Eastern and Russian Journal of Plant Science and Biotechnology 3 (Special Issue 1): 20-24.

Mohammadi, R., Haghparast, R., Amri, A. and Ceccarelli, S. 2010a. Yield stability of rainfed durum wheat and GGE biplot analysis of multi-environment trials. Crop Pasture Sci. 61: 92-101.

Mohammadi, R., Pourdad, S. S. and Amri, A. 2008. Grain yield stability of spring saflower (Carthamus tinctorius L.). Aust. J. Agric. Res. 59: 546-553.

Mohammadi, R., Roostaei, M., Ansari, Y., Aghaee, M. and Amri, A. 2010c. Relationships of phenotypic stability measures for genotypes of three cereal crops. Can. J. Plant Sci. 90: 819-830.

Mohammadi, R., Roustaii, M., Haghparast, R., Roohi, E., Solimani, K., Ahmadi, M. M., Abedi, G. R. and Amri, A. 2010 b. 
Genotype $\times$ environment interactions for grain yield in rainfed winter wheat multi-environment trials in Iran. Agron. J. 102: $1500-1510$.

Mohammadi, R., Sadeghzadeh, D., Armion, M. and Amri, A. 2011. Evaluation of durum wheat experimental lines under different climate and water regime conditions of Iran. Crop Pasture Sci. 62: 137-151.

Morris, C. F., Campbell, K. G. and King, G. E. 2004. Characterization of the end-use quality of soft wheat cultivars from the eastern and western US germplasm "pools". Plant Genet. Res. 2: 59-69.

Michigan State University. 1991. MSTATC, A software program for design, management and analysis of Agronomic Research Experiments. Michigan State University, East Lansing, MI.

Nassar, R. and Huehn, M. 1987. Studies on estimation of phenotypic stability: tests of significance for non-parametric measures of phenotypic stability. Biometrics 43: 45-53.

Ober, E. S., Bloa, M. L., Clark, C. J. A., Royal, A., Jaggard, K. W. and Pidgeon, J. D. 2005. Evaluation of physiological traits as indirect selection criteria for drought tolerance in sugar beet. Field Crops Res. 91: 231-249.

Rao, A. R. and Prabhakaran, V. T. 2005. Use of AMMI in simultaneous selection of genotypes for yield and stability. J. Ind. Soc. Agric. Statist. 59: 76-82.

Sabaghnia, N., Dehghani, H. and Sabaghpour, S. H. 2006. Nonparametric methods for interpreting genotype $\times$ environment interaction of lentil genotypes. Crop Sci. 46: 1100-1106. Samonte, S. O. P. B., Wilson, L. T., McClung, A. M. and Medley, J. C. 2005. Targeting cultivars onto rice growing environments using AMMI and SREG GGE biplot analyses. Crop Sci. 45: 2414-2424.
Thomason, W. E. and Phillips, S. B. 2006. Methods to evaluate wheat cultivar testing environments and improve cultivar selection protocols. Field Crops Res. 99: 87-95.

Voltas, J., López-Córcoles, H. and Borrás, G. 2005. Use of biplot analysis and factorial regression for the investigation of superior genotypes in multi-environment trials. Eur. J. Agron. 22: $309-324$.

Yan, W. 2001. GGE biplot - A Windows application for graphical analysis of multi-environment trial data and other types of two-way data. Agron. J. 93: 1111-1118.

Yan, W. and Rajcan, I. R. 2002. Biplot analysis of test sites and trait relations of soybean in Ontario. Can. J. Plant Sci. 42: $11-20$.

Yan, W. and Kang, M. S. 2003. GGE biplot analysis: A graphical tool for breeders, geneticists, and agronomists. CRC Press, Boca Raton, FL. 213 pp.

Yan, W. and Tinker, N. A. 2005. An integrated biplot system for displaying, interpreting, and exploring genotype 9 environment interaction. Crop Sci. 45: 1004-1016.

Yan, W., Cornelius, P. L., Crossa, J. and Hunt, L. A. 2001. Two types of GGE biplots for analyzing multi-environment trial data. Crop Sci. 41: 656-663.

Yan, W., Hunt, L. A., Sheng, Q. and Szlavnics, Z. 2000. Cultivar evaluation and mega-environment investigation based on the GGE biplot. Crop Sci. 40: 597-605.

Yan, W., Kang, M. S., Ma, B., Woods, S. and Cornelius, P. L. 2007. GGE Biplot vs. AMMI analysis of genotype-byenvironment data. Crop Sci. 47: 643-655.

Yates, F. and Cochran, W. G. 1938. The analysis of groups of experiments. J. Agric. Sci. (Camb.) 28: 556-580.

Zobel, R. W., Wright, M. J. and Gauch, H. G. 1988. Statistical analysis of a yield trial. Agron. J. 80: 388-393. 